\title{
Artérias mesentéricas cranial e caudal da paca (Cuniculus paca, L. 1766)
}

\author{
Isabela Cristina de Souza Marques \\ Sergio Pinter Garcia Filho * \\ Leandro Luis Martins \\ Leonardo Martins Leal \\ Ana Carolina Gonçalves dos Reis \\ Márcia Rita Fernandes Machado \\ Universidade Estadual Julio de Mesquita Filho \\ Via de Acesso Prof. Paulo Donato Castellane, s/n, Campus Jaboticabal \\ CEP 14884-900, Jaboticabal - SP, Brasil \\ * Autor para correspondência \\ sgarciafilho@hotmail.com
}

Submetido em 01/08/2012

Aceito para publicação em 23/10/2012

\section{Resumo}

A paca (Cuniculus paca, Linnaeus, 1766) é um roedor de porte médio, que embora pertença à fauna brasileira, poucas são as informações sobre sua morfologia na literatura especializada. Nesse sentido, objetivouse descrever a origem e as ramificações de suas artérias mesentéricas cranial e caudal no intuito de contribuir com estudos de anatomia comparativa. Foram utilizados dez animais, entre machos e fêmeas, que após o óbito, tiveram sua parede torácica rebatida entre a quarta e a sexta costelas, para a exposição da aorta torácica, a qual foi canulada no sentido caudal e procedeu-se a injeção de solução de neoprene do tipo látex, corado convenientemente, para o preenchimento de todo o sistema arterial. Estas preparações foram fixadas em solução aquosa de formol a $10 \%$ por período superior à $72 \mathrm{~h}$; em seguida, as peças foram dissecadas e as artérias mesentéricas cranial e caudal identificadas. A artéria mesentérica cranial se originava da aorta abdominal, caudalmente à artéria celíaca, emitindo os seguintes ramos arteriais: pancreaticoduodenal caudal, pancreáticos, jejunais, íleocólicos e cecais. A origem da artéria mesentérica caudal ocorria próximo ao final da aorta abdominal, e este vaso emitia a artéria cólica esquerda e a artéria retal cranial, da qual partiam as artérias sigmóideas. Constatou-se que houve pouca variação no padrão de ramificação das artérias em relação aos referidos roedores e mamíferos domésticos.

Palavras-chave: Artéria mesentérica caudal; Artéria mesentérica cranial; Paca; Ramificações

\section{Abstract}

Cranial and caudal mesenteric arteries of the paca (Cuniculus paca, L. 1766). The paca (Cuniculus paca, Linnaeus, 1766) is a medium-sized rodent that occurs in Brazil; however, there is little information regarding its morphology. The goal of this study was to describe the origin and branching of the cranial and caudal mesenteric arteries of this rodent in order to contribute to comparative anatomy studies. Ten animals (males and females) 
were used. After death, their thoracic inlet was opened between the fourth and sixth ribs to expose the thoracic aorta, which was cannulated caudally. A stained, neoprene latex solution was then injected, in order to fill the arterial system, and the preparations were fixed in a 10\% aqueous formalin solution for over $72 \mathrm{~h}$. The fixed specimens were dissected to identify the cranial and caudal mesenteric arteries. The cranial mesenteric artery started at the abdominal aorta, caudally to the celiac artery, and originated in the following arterial branches: caudal pancreatic duodenal, pancreatic, jejunal, ileum colic and cecal. The origin of the caudal mesenteric artery occurred next to the end of abdominal aorta and this vessel issued the left colic artery and cranial rectal artery from which the sigmoid arteries initiated. It was found that there was little difference in the branching pattern of the arteries compared to other rodents and domestic mammals.

Key words: Caudal mesenteric artery; Cranial mesenteric artery; Paca; Ramifications

\section{Introdução}

A paca é o segundo maior roedor da fauna brasileira, apresenta corpo robusto e vigoroso, nos machos e fêmeas adultos, o comprimento médio entre o nariz e a ponta da cauda é de $70 \mathrm{~cm}$ e $60 \mathrm{~cm}$, respectivamente e o peso corpóreo varia de 5 a $10 \mathrm{~kg}$, podendo chegar até aos $14 \mathrm{~kg}$ (MONDOLFI, 1972; MATAMOROS, 1982).

Sua importância, além da comercial, toma também o âmbito da ciência podendo ser uma boa alternativa para fins de pesquisa, colaborando com o desenvolvimento de investigações vitais ao homem e aos próprios animais.

Segundo Greene (1955), a artéria mesentérica "superior" do rato é um grande vaso oriundo da porção abdominal da aorta que cruza ventralmente a veia cava inferior. Ela dá origem a um ramo pancreático-duodenal "inferior" para o pâncreas e para a primeira alça do duodeno, e uma série de ramos intestinais para o jejuno e íleo; um ramo ileocólico para o íleo, ceco e primeira parte do cólon; um ramo cólico direito, que às vezes se origina com o ileocólico, para suprir o cólon ascendente; um ramo cólico médio para o cólon transverso. O autor acrescenta que o ramo ileocólico se anastomosa com um ramo da artéria mesentérica "inferior".

Cook (1965) observou que a artéria mesentérica "superior", em camundongos, emite ramos para o pâncreas e duodeno e para diversas partes do intestino delgado e grosso, sendo que um de seus ramos é direcionado ao ceco e cólon, e a artéria mesentérica "inferior" irriga partes do reto.

Segundo Schwarze e Schröder (1972); Getty (1981) e Nickel et al. (1981), a artéria mesentérica cranial origina-se caudalmente à artéria celíaca, com a qual forma em alguns casos um tronco. A artéria mesentérica caudal é um vaso ímpar que se origina próximo à divisão terminal da aorta, dividindo-se após um curto trajeto.

Orsi et al. (1975) afirmam que o comportamento dos ramos viscerais da aorta abdominal, destinados aos segmentos abdominais do aparelho digestório do hamster dourado (Mesocricetus auratus), assemelha-se ao de outros mamíferos, tais como a cobaia, o coelho, o rato e o homem.

A artéria mesentérica cranial nasce imediatamente ventral ao tronco celíaco, seguindo em direção caudal, penetra entre as folhas do mesentério na sua extensão e segue trajeto arciforme até chegar à extremidade final do intestino delgado, de onde se origina a artéria pancreático-duodenal caudal, esta se dirige à direita nutrindo o duodeno e o pâncreas. Em alguns casos existem anastomoses dos seus ramos com a artéria pancreaticoduodenal cranial (ORSI et al., 1975).

Aproximadamente, são sete artérias jejunais, sendo que cinco destas emergem de um tronco jejunal comum. Deste tronco, duas destinam-se ao jejuno e três ao íleo. As ileais são representadas pela artéria ileocólica que nasce do lado direito da artéria mesentérica cranial e vasculariza o íleo, ceco e porção inicial do cólon; pela artéria cólica direita que nasce do lado direito da artéria mesentérica cranial e vasculariza o cólon ascendente e pela artéria cólica média a qual emerge como as outras do lado direito e irriga o cólon transverso e a parte inicial do cólon descendente (ORSI et al., 1975).

A artéria mesentérica caudal é o último ramo visceral da aorta abdominal, sendo ímpar e emerge na 
maioria dos casos da face ventral da aorta, no ponto de bifurcação ao formar as artérias ilíacas comuns, podendo também nascer de uma destas últimas artérias, emitindo um ramo descendente, a artéria retal cranial para o reto, e um ramo ascendente a artéria cólica esquerda para o cólon descendente (ORSI et al., 1975; HABEL; STROMBERG, 1986).

Habel e Stromberg (1986) relatam que a artéria mesentérica cranial do rato emerge da aorta $3-5 \mathrm{~mm}$ caudalmente a artéria celíaca. Ela dá origem a uma artéria cólica média dupla que supre o cólon transverso e a porção inicial do cólon descendente. Às vezes ela se anastomosa com a artéria cólica esquerda. O próximo vaso que se origina da artéria mesentérica cranial é a pancreaticoduodenal caudal, que se divide em ramos direito e esquerdo, dando origem a dois ramos pancreáticos e um para o duodeno o qual se bifurca numa porção cranial e numa caudal. O segundo ramo percorre a porção ascendente do duodeno. Ambos os ramos se anastomosam entre si e com as artérias intestinais adjacentes.

A artéria cólica direita dirige-se ao cólon ascendente e se divide anastomosando-se com as artérias jejunais, as quais percorrem o jejuno e a parte proximal do íleo. A principal continuação da mesentérica cranial, a artéria íleocólica oferece um ramo cólico para o cólon ascendente, um ramo ileal para o íleo e à semelhança da artéria cecal percorre o ceco próximo à abertura do íleo. Aí se bifurca e se ramifica ao longo da pequena curvatura do ceco (HABEL; STROMBERG, 1986).

Segundo Barone et al. (1973), a artéria mesentérica cranial do coelho emite a artéria cólica média, a artéria pancreático-duodenal caudal, a artéria cólica direita, um ramo ileocólico e um troco comum, as artérias jejunais. A artéria mesentérica caudal se divide em artéria cólica esquerda e artéria retal cranial da qual partem as artérias sigmóideas.

Carvalho et al. (1999) relataram que a artéria mesentérica cranial, em cutias (Dasyprocta aguti), divide-se por bifurcação, trifurcação ou quadrifurcação, dando origem à diversos ramos que irrigam porções do intestino e do pâncreas. Para estes autores, a artéria mesentérica caudal bifurca-se vascularizando as porções finais do intestino grosso e reto. O autor também verifica anastomoses entre ramos originários da artéria mesentérica cranial e com os derivados da artéria mesentérica caudal.

Considerando-se que dados sobre a morfologia detalhada da paca são poucos, nesse sentido, objetivouse descrever a origem e a ramescência das artérias mesentéricas cranial e caudal da paca.

\section{Material e Métodos}

Foram utilizadas dez pacas adultas, cinco machos e cinco fêmeas, excedentes do plantel do Setor de Animais Silvestres do Departamento de Zootecnia da Faculdade de Ciências Agrárias e Veterinárias de Jaboticabal UNESP, as quais foram descartadas para a seleção e manutenção do equilíbrio entre machos e fêmeas no criatório estabelecido neste setor com registro junto ao Instituto Brasileiro do Meio Ambiente e dos Recursos Naturais Renováveis - IBAMA como criatório de espécimes da fauna brasileira para fins científicos, sob número de cadastro: 482508 .

Relativamente à eutanásia dos animais, esta foi efetuada mediante administração de sobredose dos agentes que usualmente se emprega para anestesiar esses animais, ou seja, para anestesia desses roedores administra-se, $1 \mathrm{mg}$ midazolan por quilo de peso corpóreo, via intramuscular, além da associação de $20 \mathrm{mg}$ por quilo de peso corpóreo de cloridrato de quetamina com 1,5mg de cloridrato de xilazina, ambos na mesma seringa e aplicados via intramuscular.

Após o óbito destes animais, realizou-se a abertura da cavidade torácica, rebatendo as quarta, quinta e sexta costelas, expondo a aorta torácica, a qual foi canulada para posterior injeção de látex, do tipo neoprene corado com corante vermelho, infundindo-se no sentido caudal, até que todo sistema arterial fosse devidamente preenchido.

Os exemplares foram fixados por infusão intramuscular em solução aquosa de formol a $10 \%$ por período superior à $72 \mathrm{~h}$. Os animais foram dissecados, identificando-se inicialmente a origem das artérias mesentéricas cranial e caudal e suas ramificações 
viscerais. Na sequência foi realizada a fotodocumentação do material analisado.

\section{Resultados e Discussão}

No que se refere à origem da artéria mesentérica cranial da paca, foi observado que este vaso, semelhante ao citado pelos autores (GETTY, 1981; NICKEL et al., 1981), no rato (GREENE, 1955; HABEL; STROMBERG, 1986), no mocó (QUEIROZ et al., 2011) e no coelho da Nova Zelândia (MACHADO et al., 2008), originava-se da aorta abdominal, caudalmente à artéria celíaca (Figura 1). Orsi et al. (1975) relatam em seus estudos que a artéria mesentérica cranial do hamster dourado é ímpar e nasce imediatamente ventral ao tronco celíaco, diferente ao visualizado em nosso estudo. Outra diferença notada em pacas esta relacionada à origem em tronco da mesentérica cranial.

Em pacas foi observado que a artéria mesentérica caudal originava-se na altura da divisão terminal da aorta abdominal, assim como ocorre nos animais domésticos (SCHWARZE; SCHRÖDER, 1972; GETTY, 1981;
NICKEL et al., 1981) e no coelho da Nova Zelândia (MACHADO et al., 2008) (Figura 2).

Não se constatou no presente estudo, nem na literatura consultada, origem da artéria mesentérica caudal igual aos relatos de Orsi et al. (1975) para hamster dourado, no qual nestes animais, este vaso emerge no ponto de bifurcação da aorta, quando se formam as artérias ilíacas comuns.

Sobre a ramescência da artéria mesentérica cranial, semelhante a Cook (1965) para o camundongo de laboratório, Carvalho et al. (1999) para a cutia, Machado et al. (2008) para o coelho da raça Nova Zelândia e Queiroz et al. (2008) para o mocó, também se verificou que este vaso emitiu ramos para o pâncreas e duodeno e para diversas partes do intestino delgado e grosso, embora Cook (1965) não identifique os ramos e tampouco os seus trajetos.

Nossos achados assemelham-se as descrições de Greene (1955) e de Habel e Stromberg (1986), para ratos; de Barone et al. (1973), para coelhos, de Orsi et al. (1975), para hamster, de Nayar et al. (1983), para caprinos, carnívoros, suínos e coelhos, de Carvalho et

FIGURA 1: Fotomacrografia da origem da artéria mesentérica cranial de pacas. Verificar o ramo principal da artéria mesentérica cranial (mcr), originando-se da artéria abdominal (A), e localizada caudalmente a artéria celíaca (c). Em R nota-se o rim esquerdo.

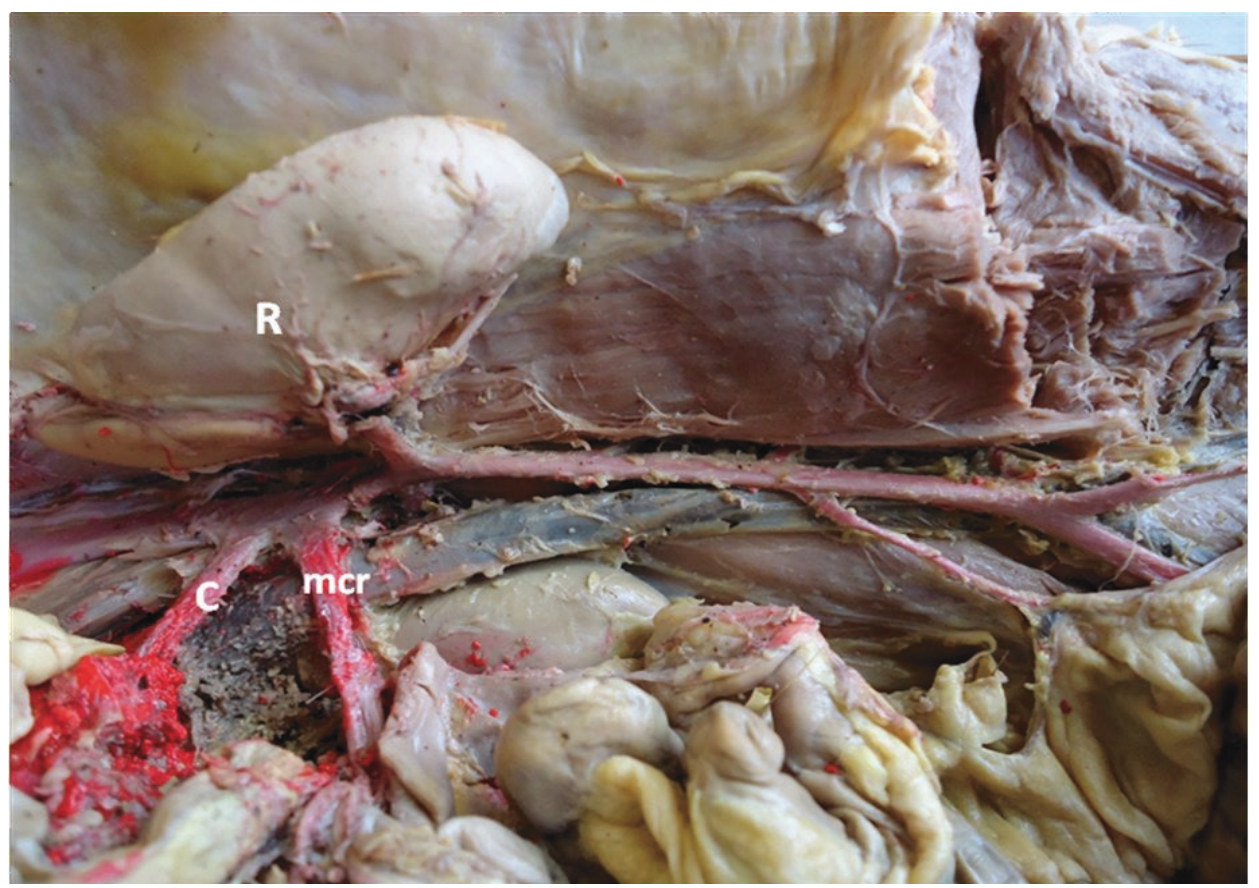


FIGURA 2: Fotomacrografia da artéria mesentérica caudal de paca (Agouti paca). Observar no detalhe a artéria mesentérica cranial (mc) e caudalmente a artéria mesentérica caudal (md), ambas se originando da aorta abdominal (A), pouco antes desta se bifurcar em artérias ilíacas (I).

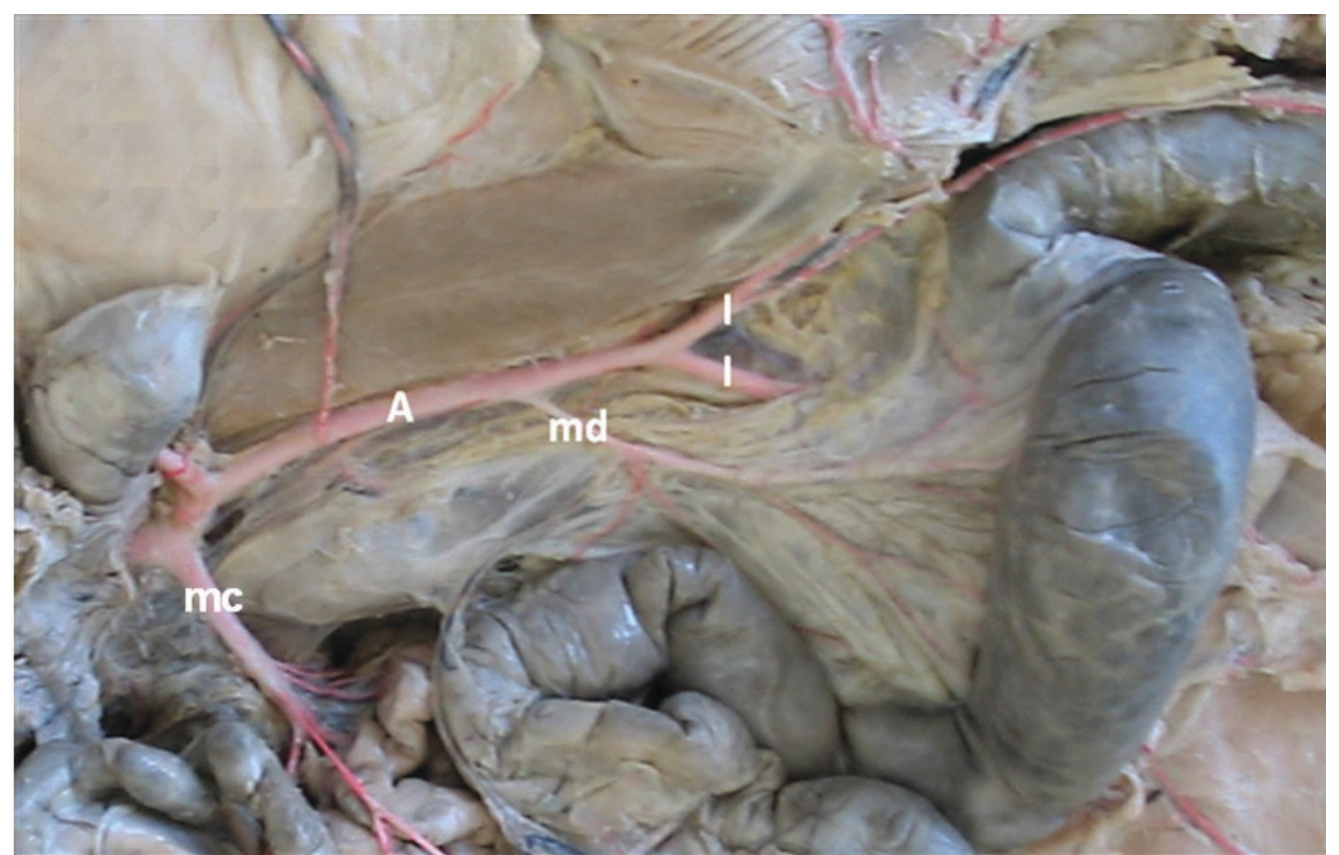

al. (1999), para a cutia, de Machado et al. (2008), para o coelho, da raça Nova Zelândia e de Queiroz et al. (2011), para o mocó, quando relataram que a artéria mesentérica cranial originava as artérias pancreaticoduodenal caudal, ileocecocólica e ramos jejunais (Figura 3), descrição diferente foi realizada por Habel e Stromberg (1986), estes autores não constataram a presença de artéria cólica média dupla nas preparações.

Também não foram verificadas, nos espécimes analisados, anastomoses entre as artérias gastroepiplóica esquerda e cólica média como citado por Nayar et al. (1983), para coelhos e carnívoros, e por Machado et al. (2008), para o coelho da Nova Zelândia; embora Nayar et al. (1983) e Carvalho et al. (1999), os autores afirmam que a artéria ileocecocólica aparece como primeiro ramo da artéria mesentérica cranial. Nas pacas observou-se a ocorrência da artéria pancreático duodenal caudal como primeiro ramo da mesentérica cranial, da mesma forma que Greene (1955) relatou para ratos, Barone et al. (1973) para coelhos e Orsi et al. (1975) para hamster dourados. Tal qual descreveram Nayar et al. (1983), Orsi et al. (1975), Carvalho et al. (1999) e Queiroz et al. (2011), também, constatou- se a artéria ileocecocólica como um ramo da artéria mesentérica cranial em pacas.

Não obstante, tenha-se verificado a presença de numerosas artérias jejunais, da mesma forma que citaram Nayar et al. (1983) para todas as espécies por eles estudadas, não havia a ocorrência de tronco jejunal na paca, como referiram, Barone et al. (1973) para coelhos, Orsi et al. (1975) para hamster dourados, Carvalho et al. (1999) para cutias e Queiroz et al. (2011) para o mocó.

Embora achados deste estudo assemelhem-se aos observados na cutia (CARVALHO et al., 1999), relativamente à identificação e à distribuição dos vasos, não se verificou a ocorrência dos diversos arranjos de divisão inicial da artéria mesentérica cranial nas pacas, como descreveram estes autores.

No que se refere à ramescência da artéria mesentérica caudal, ora observada, este vaso, após curto trajeto em direção ao cólon menor, dividiu-se em artéria cólica esquerda e artéria retal cranial, da qual partiram as artérias sigmóides (Figura 4). Tais observações são semelhantes às descrições de Orsi et al. (1975), para hamster dourados, de Machado et al. (2008), para coelho 
FIGURA 3: Fotomacrografia da artéria mesentérica cranial da paca (Agouti paca). Observar no detalhe a artéria mesentérica cranial (mcr) emitindo a artéria pancreáticoduodenal caudal (seta amarela); artéria cólica média e seus ramos (seta verde) distribuídos no cólon menor. Notar a artéria cólica direita, distribuindo-se na porção espiral do cólon maior (seta branca).

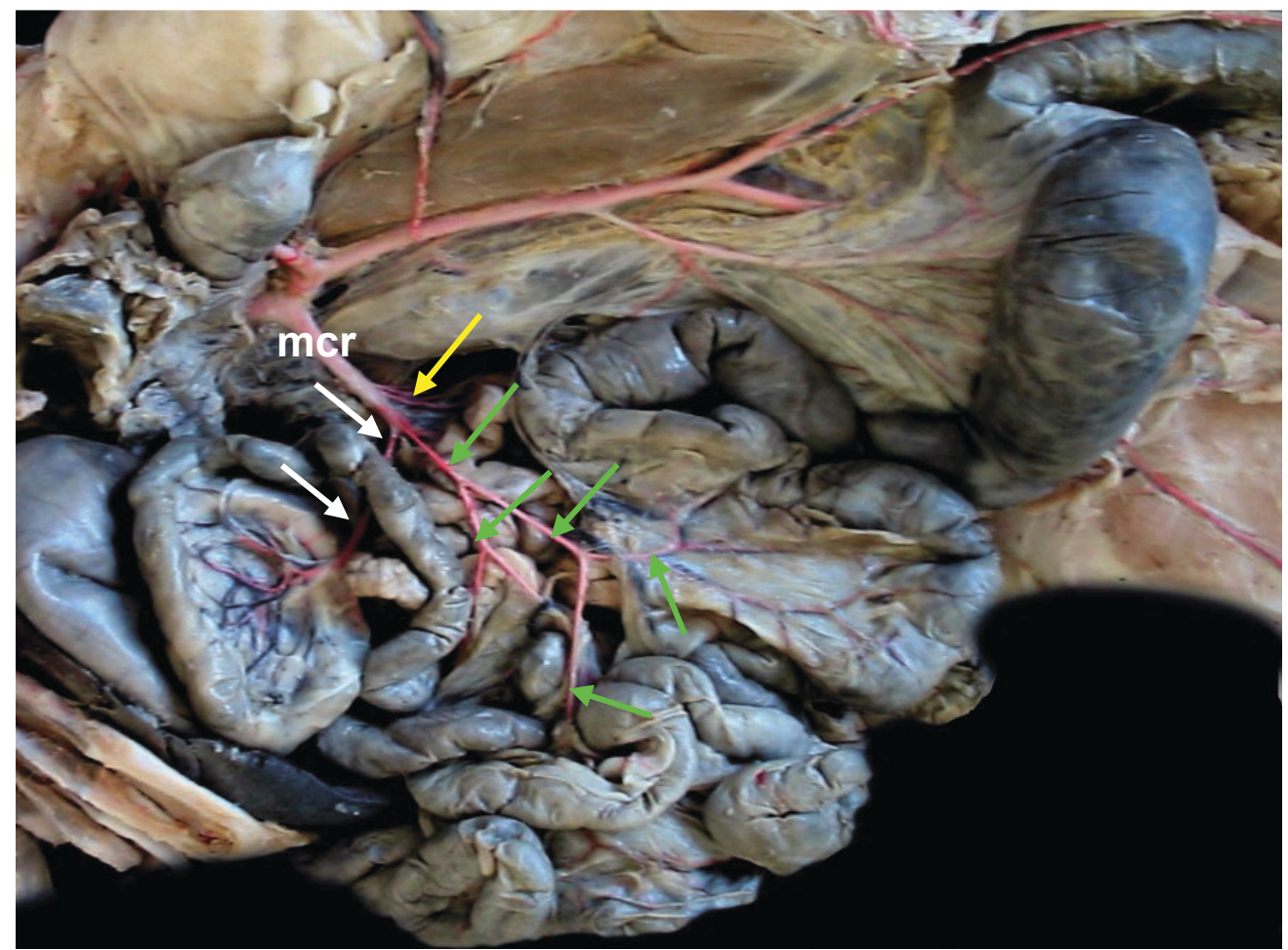

FIGURA 4: Fotomacrografia das artérias mesentéricas cranial e caudal da paca (Agouti paca). Observar no detalhe, a artéria mesentérica cranial (mcr) e artéria mesentérica caudal (mca) emitindo seus ramos para o cólon menor (seta verde).

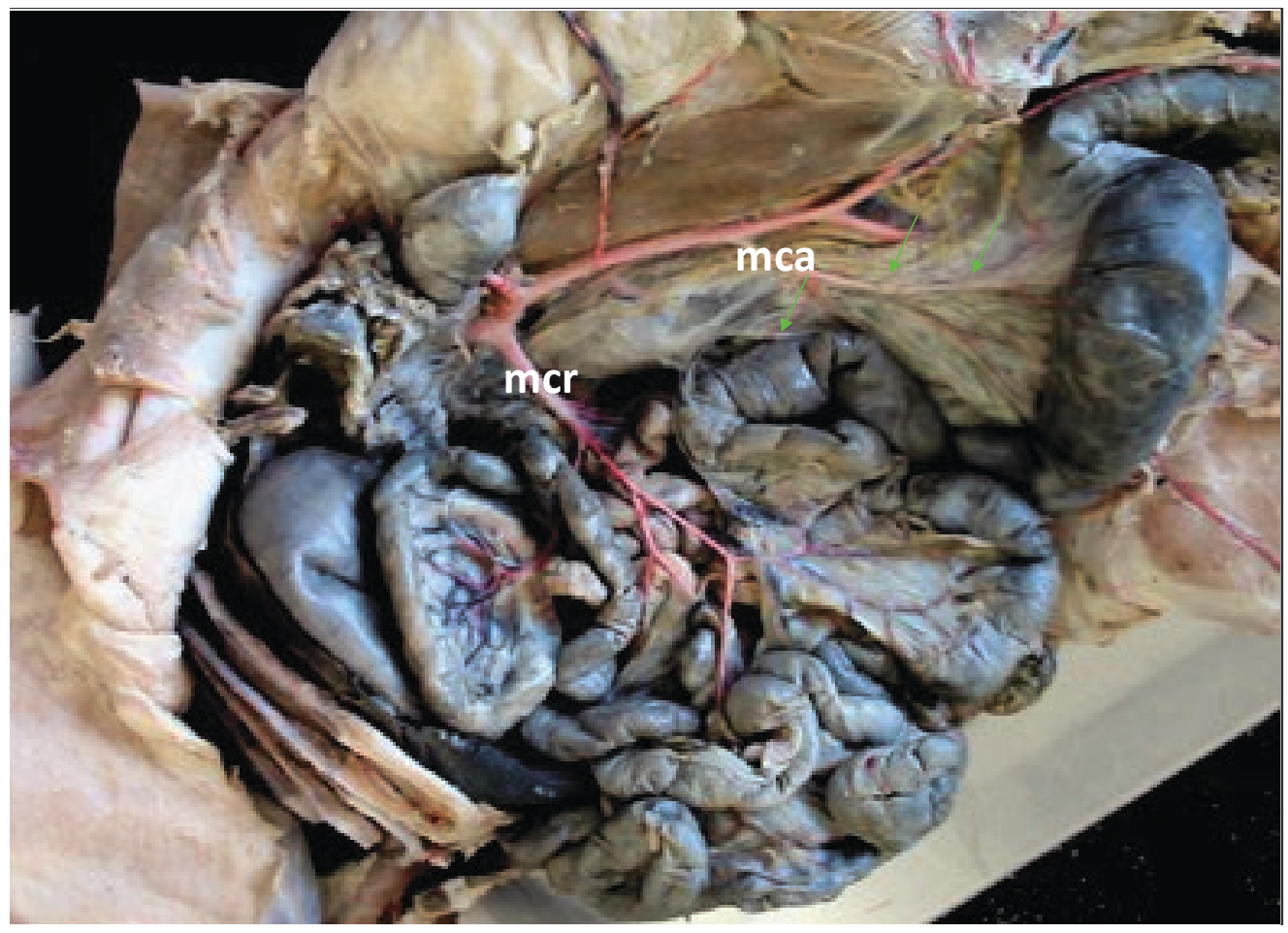


da Nova Zelândia, de Queiroz et al. (2011), para mocós, e de Habel e Stromberg (1986), para ratos, conquanto estes autores não mencionam ocorrência das artérias sigmóides.

Barone et al. (1973) em estudos com coelhos e Carvalho et al. (1999) em cutias, constataram a mesma distribuição para a artéria mesentérica caudal, que foi observada na paca. Da mesma forma que relataram Carvalho et al. (1999) para cutias também verificou-se na paca várias anastomoses entre os ramos da artéria mesentérica cranial e artéria mesentérica caudal.

Pôde-se constatar que, das amostras analisadas, houve pouca variação no padrão de ramificação tanto da artéria mesentérica cranial como da artéria mesentérica caudal em relação aos referidos roedores e mamíferos domésticos.

\section{Referências}

BARONE, R.; PAVAUX, C.; BLIN, P. C.; CUQ, P. Atlas D'Anatomie du Lapin. Paris: Masson, 1973. 219 p.

CARVAlHO, M. A. M.; MIGLINO, M. A.; DIO, L. J. A.; MELO, A. P. F. Artérias mesentéricas cranial e caudal em cutias (Dasyprocta aguti). Journal of Veterinary Science Federal University of Uberlândia, Uberlândia, v. 5, n. 2, p. 17-24, 1999.

COOK, J. M. The anatomy of the laboratory mouse. London: Academic Press, 1965. 143 p.

GETTY, R. Anatomia dos animais domésticos. Rio de Janeiro: Interamericana, 1981. $1962 \mathrm{p}$.
GREENE, G. C. Circulatory system. In: GREENE, G. C. (Ed.). Anatomy of mammals. New York: Transactions of the American Philosophical Co, 1955. p. 177-235.

HABEL, R.; STROMBERG, M. W. Anatomy and Embryology of the laboratory rat. Berlin: Biomed Verlag, 1986. 270 p.

MACHADO, M. R. F.; SOUZA, S. V.; OLIVEIRA, T. C.; CORTELLINI, L. M. F.; BARBOSA, R. R. Suprimento arterial dos intestinos do coelho da raça Nova Zelândia (Oryctolagus cuniculus). Biotemas, Florianópolis, v. 21, n. 1, p. 101-105, 2008.

MATAMOROS, Y. Investigaciones preliminares sobre $\mathrm{La}$ reproduccion, comportamiento, alimentacion y manejo tapezcuinte (Cuniculus paca, Brisson) en cautiverio. In: CONGRESSO LATINOAMERICANO DE ZOOLOGIA, 8, 1982, Merida. Anais... Merida: Zoologia Neotropical, 1982. p. 961-992.

MONDOLFI, E. La laca o paca. Defensa de la naturaleza, Caracas, v. 2, n. 5, p. 4-16, 1972.

NAYAR, K. N. M.; SINGH, G.; SINGH, Y., SINGH, A. P.; SINGH, G. R. Comparative arteriographic anatomy of the abdominal viscera and lumbar region in goats, dogs, pigs and rabbits. Indian Journal of Animal Sciences, New Delhi, v. 53, n. 12, p. 1310-1419, 1983.

NICKEL, R.; SCHUMMER, A.; SEIFERLE, E.; SACK, W. O. The circulatory system, the skin, and the cutaneous organs of the domestic mammals. Berlin: Verlag Paul Parey, 1981. 588 p.

ORSI, A. M.; PINTO E SILVA, P.; MELLO-DIAS, S.; OLIVEIRA, M. C. Considerações sobre a remescência da aorta abdominal do Hamster dourado (Mesocricetus auratus). Revista Brasileira de Pesquisas Médicas e Biológicas, São Paulo, v. 8, n. 5-6, p. 459462, 1975.

QUEIROZ, P.V. S.; MOURA, C.E. B.; LUCENA, J.A.; OLIVEIRA, M. F.; ALBUQUERQUE, J. F. G. Artérias mesentéricas cranial e caudal em mocós Kerodon rupestris (Wied, 1820). Pesquisa Veterinária Brasileira, Rio de Janeiro, v. 31, n. 7, p. 623-626, 2011.

SCHWARZE, E.; SCHÖDER, L. Compendio de anatomia veterinaria: aparato circulatório y piel. Zaragoza: Acribia, 1972. $247 \mathrm{p}$. 